Function and Disability Journal ISSN: 2588-6304

Original Article

\title{
Validity and Reliability of Persian Version of COMI-Neck Questionnaire in Iranian Patients with Chronic Neck Pain
}

\author{
Morteza Rafatifard ${ }^{1}$, Shabnam Shahali ${ }^{2}$, Soheil Mansour Sohani ${ }^{* *}$
}

1. MSc Student, Department of Physiotherapy, School of Rehabilitation Sciences, Iran University of Medical Sciences, Tehran, Iran

2. Assistant Professor, Department of Physiotherapy, School of Rehabilitation Sciences, Iran University of Medical Sciences, Tehran, Iran

\begin{tabular}{c}
\hline Article Info \\
\hline Received: $2018 / 05 / 08$ \\
Accepted: $2018 / 07 / 25$ \\
Published Online: $2018 / 10 / 29$ \\
DOI: 10.30699/fdisj.01.2.57 \\
How to Cite This Article \\
Rafatifard M, Shahali SH, \\
Mansour Sohani S. Validity \\
and Reliability of Persian \\
Version of COMI-Neck \\
Questionnaire in Iranian \\
Patients with Chronic Neck \\
Pain. Function and Disability \\
Journal. 2018 (spring).Vol: \\
1.No:2 Pages: $57-64$ \\
\end{tabular}

Use your device to scan and read the article online

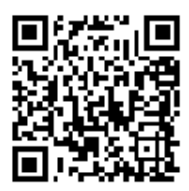

\begin{abstract}
Background and Objectives: Chronic neck pain in various ages is one of the important causes of occupational disability which has imposed huge costs on health services. Therefore, developing a valid and reliable instrument to obtain information about patients with neck pain seems necessary. The present study was conducted to examine the psychometric properties of COMI-Neck questionnaire in Iranian patients with chronic neck pain.
\end{abstract}

Methods: In this study, in order to examine reliability (test-retest and internal consistency), the Persian version of The Core Outcome Measures Index for the neck (COMI-Neck), was completed using convenience sampling method among 100 patients with chronic neck pain attending rehabilitation clinics in Karaj city. In order to examine validity, FRI, NDI and SF-36 questionnaires were also completed by participants. Internal consistency, reliability, discriminate validity and construct validity were analyzed using SPSS 20 and statistical tests.

Results: The ICC test results for scores of 5 indices including pain, daily activities, adaptability to existing symptoms, quality of life, recreational and social activities in COMI-Neck, showed that very high validity of the questionnaire with Cronbach's alpha of 0.89 . There was strong correlation between the total score of COMI-Neck and the total score of FRI $(P<0.05)$. Also, a strong correlation existed between the total score of COMI-Neck and NDI total score $(P<0.05)$. Strong and reverse correlations were observed between score of all scales of COMI-Neck and the total score of SF-36 $(P<0.05)$.

Conclusion: The Persian version of The Core Outcome Measures Index for the neck (COMI-Neck) showed good validity and reliability in evaluation of outcome measures among Iranian patients with chronic neck pain.

Keywords: Validity, Reliability, Chronic neck pain, COMI-Neck Questionnaire

Corresponding Information:

Soheil Mansour Sohani, Assistant Professor, Department of Physiotherapy, School of Rehabilitation Sciences, Iran University of Medical Sciences, Tehran, Iran Email: mansorsohani.s@iums.ac.ir Tel: +982122228051

Copyright (C) 2018, Function and Disability Journal. This is an original open-access article distributed under the terms of the Creative Commons Attribution-noncommercial 4.0 International License which permits copy and redistribution of the material just in noncommercial usages with proper citation.

\section{Introduction}

Chronic neck pain is one of the most prevalent disorders in today's societies. This disorder as a vocational disability has imposed a lot of expenses on health services. About $1 \%$ of whole budget in health-care system is spent for medical interventions every year. The prevalence of neck pain in people's life is contemplated
$50 \%$. Due to the increasing prevalence of neck pain and accompanying problems including: depression, difficulties in interpersonal relationships and falling sleep, fatigue and reduced physical and psychological, functions considering the patients' insights for having influential interventions should be assessed. One of the necessary actions for managing the pain is a comprehensive evaluation and the obtained information should 
be repeatable. In recent years the outcomes evaluation from objective indices and imaging has moved towards subjective and patient-oriented scales. But according to literature just a few numbers of these instruments (questionnaire) have been standardized and as a result comparing the various studies is unachievable. In 1998 Deyo et al. created a standardized evaluation instrument of outcomes named COMI for people with back pain. The COMI questionnaire has been designed for people with back pain to assess pain, function, general health, disability and satisfaction, in which clinical outcomes of lumbar disc or spinal cord stenosis are measured in 5 subscales assessing pain (2 questions), function (1 question), general health (1 question), disability (1 question), satisfaction (1 question). These specialists utilized the valid instruments from previous studies (ODI, RMQ) and public questionnaires (SF-36 and SF-12). Such dimensions of outcome are also included in AAOS and NASS which indicate agreement on these dimensions among outcomes of back pain. The COMI questionnaire for assessing the outcomes following surgical or nonsurgical treatments has been registered in European spine society. This questionnaire has been culturally adapted to different languages including: French, German, Italian, Polish, Norwegian, Hungarian, Brazilian-Portuguese, Chinese, and Persian. A zero-to-ten graphical scale is applied to evaluate the pain in patients with back pain in which zero shows the best condition and ten shows the worst condition in patients. Psychometric characteristics of this questionnaire has been separately reviewed in several studies and its validity and reliability have been examined. COMI questionnaire is brief and encompasses outstanding psychometric features for patient undergone surgical and non-surgical treatments. In 2004, the COMI questionnaire was also applied to neck pain patients in a way that shoulder pain was replaced with neck and known as COMI-NECK. This questionnaire is completed by patients less than two minutes. Ease in completion and interpretation, has introduced this questionnaire as an appropriate one. Regarding the lack of valid and reliable instruments to assess chronic neck pain, aforementioned issues, and increasing incidence of neck pain in people, the present study has been done to culturally adapt the COMI-NECK questionnaire in patients with chronic neck pain.

\section{Materials and Methods}

The present study conducted as a methodological one to assess the validity and reliability of the COMI in patients with chronic neck pain. To evaluate the construct validity of COMI questionnaire, SF-36, NDI, and FRI questionnaires were also completed by 50 patients with chronic neck pain. Then the internal consistency and stability of the questionnaire were examined. The internal validity of correlation of questions in each item from questionnaire and the whole questionnaire were calculated using Cronbach's alpha index. Cronbach's alpha values above 0.7 represent an acceptable internal consistency of the instrument. Test-retest method was used to verify consistency of the instrument over time. To gather the information, sampling started after receiving ethics code from university ethics committee (IR.IUMS.REC1395.92113402021). Participants were recruited from orthopedic centers and physical therapy clinics in Karaj city using random sampling. The number of samples was 100 participants based on similar studies in this field and also suggested criteria by Terwee and et al. The criteria for entering the study were: age over 18, neck pain for more than 3 months, Iranian nationality, and minimum education of primary school. Criteria for leaving the group included: having neck pain due to deformity, cervical spinal cord fracture, existing central or peripheral nervous disorders, having systematic diseases (tumor or articular diseases), using pain medication, and cognitive and mental disorders. First, the relevant data such as the duration of the disease, frequency of neck pain in the past year, and occupational leave days from the work. Then the second part of the questionnaire with Persian edition of FRI, NDI, and SF-36 were completed. To assess the validity of the distinction, the questionnaires were completed by 50 patients with neck pain and 50 healthy subjects in two stages in a period of 7 to 10 days. COMI-Neck questionnaire is designed based on a 10-question graphical model, the score calculation is such a way that 0 score indicates the best condition and the score of 10 indicates the worst condition in patients. 
FRI questionnaire has 10 questions for evaluating pain and function of patients with neck pain in which each question has 5 modes ( 0 : No pain with enough ability to perform function, Score 4: The worst pain and disability to perform function) based on the patient's understanding of his disability For performance or severity of pain at the present time. Validity and reliability of the Persian version of the FRI standard questionnaire have been checked by Ansari et al. (2016) and approved by Cronbach's alpha of 0.88 (Genevay et al., 2012). The NDI questionnaire was used to evaluate functional disability in patients with neck pain and includes pain intensity, ability to do personal work, lifting, studying, headache, concentration, work, driving, sleep and recreational activities, which have been graded based on a six-level scale. So, by summing up the scores of questions and converting them to zero (the worst possible), it is calculated up to 100 (best possible). The validity and reliability of the Persian version of this questionnaire was examined by Mousavi et al. (2007). And is approved by the Cronbach's alpha of 0.79 (Genevay et al., 2012). The SF-36 questionnaire is a standard measurement tool for health outcomes and has 36 questions in 8 scales incorporating: physical activity scale, functional limitations due to physical problems, physical pain, general health, vitality, social function, functional limitations due to psychological problems, and mental health. Validity and reliability of the Persian version of this questionnaire was reviewed by Montazeri et al. (2005). And confirmed by Cronbach's alpha of 0.70 (White et al. 2004). In this study, statistical analysis of the data was done by SPSS software version 21 for Cronbach's alpha estimation and determination of tool stability and repeatability evaluation at test times using Spearman correlation coefficient, absolute ICC and Mann-Whitney test.

\section{Results}

In the present study, out of 100 patients, $51 \%$ were women and $49 \%$ were male. The mean duration of neck pain in patients was $13.03 \pm 10.4$ months. Other demographic characteristics of the samples studied are shown in Table 1. The mean total score of COMI-Neck in the patients with chronic neck pain was $4.69 \pm 2.10$ (at least 0.7 , at most 9.5 ) and in healthy subjects $0.62 \pm 0.66$ (at least 0 , maximum 2.5). Thus the mean of total score in the group of patients with chronic neck pain was significantly higher than the healthy group. The Cronbach's alpha coefficient in the pain index (0.91), the index of daily tasks (0.92), the index of compatibility with the current symptoms (0.91), quality of life index (0.87), recreation and social activity (0.96). In the ICC test-retest, from 0.77 to 0.93 for each index of the COMI-Neck questionnaire, the total score for the questionnaire was 0.97 . The results of ICC's correlation coefficient for each of the five pain indices are above 0.89 , which indicates a high degree of validity for the quality of life indicator. Therefore, COMI-Neck questionnaire indices have a correlation with the evaluation of chronic neck pain patients $(P<0.05)$ (Table 2).

Based on the other result of this study, there was a high correlation between the total score of COMINeck questionnaire and FRI total score $(\mathrm{r}=0.775$ and $P<0.001$ ) (Table 3 ). Also, there was a high correlation between the total score of COMI-Neck questionnaire with total score of NDI ( $\mathrm{r}=0.833$ and $P<0.001)$ (Table 4). The results of Spearman correlation coefficient test showed a significant and inverse correlation between the accomplishments of tasks index in The COMI-Neck questionnaire and the mean score of SF-36 ( $P>0.05)$. By increasing the COMI-Neck index score, the total score of SF 36 was sharply reduced (Table 5).

The results of the Spearman correlation coefficient test showed a significant and inverse correlation between the indexes of compatibility index with the current symptoms in the COMI-Neck questionnaire with all the indices of the SF-36 questionnaire $(P>0.05)$. The results of Spearman correlation coefficient test showed a significant and inverse correlation between the quality of life score in the COMI-Neck questionnaire and all the indices of the SF-36 questionnaire $(P<0.05)$. The results of Spearman correlation coefficient test showed a significant and inverse correlation between the index of recreation and social activities in the COMI-Neck questionnaire with all the indices of the SF-36 questionnaire $(P<0.05)$. 
Table 1: descriptive information of patients with neck pain

\begin{tabular}{|c|c|c|}
\hline (percent)frequency & \multicolumn{2}{|c|}{ Demographic data } \\
\hline $51(51)$ & female & \multirow{2}{*}{ Gender } \\
\hline$(49) 49$ & male & \\
\hline$(42) 42$ & clerk & \multirow{4}{*}{ job } \\
\hline (26)26 & House keeper & \\
\hline (24)24 & Self-employment & \\
\hline$(8) 8$ & College student & \\
\hline$(5) 5$ & elementary & \multirow{5}{*}{ education } \\
\hline$(27) 27$ & diploma & \\
\hline$(14) 14$ & associate & \\
\hline$(42) 42$ & bachelor & \\
\hline (12)12 & master & \\
\hline (73) 73 & Less than a year & \multirow{3}{*}{ The period of neck pain } \\
\hline (18) 18 & Between 1-2 years & \\
\hline$(9) 9$ & More than 2 years & \\
\hline$(41) 41$ & No day & \multirow{4}{*}{ The period of occupational leave days } \\
\hline$(40) 40$ & Less than 10 days & \\
\hline$(10) 10$ & between 10-20days & \\
\hline (9)9 & More than 20 days & \\
\hline
\end{tabular}

Table 2: Correlation between COMI-Neck Questionnaire Indices in Patient Test and Re-test

\begin{tabular}{|c|c|c|c|c|c|}
\hline $\begin{array}{l}\text { Recreation and } \\
\text { social activities }\end{array}$ & Quality of life & $\begin{array}{c}\text { Compatibility } \\
\text { with current } \\
\text { symptoms }\end{array}$ & $\begin{array}{c}\text { Daily } \\
\text { occupations } \\
\text { performance }\end{array}$ & Pain & Indices \\
\hline 0.969 & 0.872 & 0.917 & 0.92 & 0.914 & Cronbach's alpha \\
\hline 0.939 & 0.772 & 0.847 & 0.852 & 0.842 & ICC correlation coefficient \\
\hline
\end{tabular}

Table 3: Correlation between the total score of COMI-Neck and FRI questionnaires

\begin{tabular}{cccc}
$\begin{array}{c}\text { Total score } \\
\text { FRI }\end{array}$ & $\begin{array}{c}\text { Total score } \\
\text { COMI-Neck }\end{array}$ & Index & Indices \\
\hline 0.775 & 1 & Spearman correlation coefficient & Total score \\
\hline$P<0.000 *$ & -- & Test result & COMI-Neck \\
100 & 100 & Sample size & Total score \\
1 & 0.775 & Spearman correlation coefficient & FRI
\end{tabular}


61. CValidity and Reliability of Persian Version of COMI-Neck......

Table 4: Correlation between total score of COMI-Neck and NDI questionnaires

\begin{tabular}{cccc} 
Total score & Total score & Index & Indices \\
NDI & COMI-Neck & Spearman correlation coefficient & Total score \\
\hline 0.833 & 1 & Test result & COMI-Neck \\
\hline$P<0.000 *$ & -- & Sample size & Total score \\
\hline 100 & 100 & Spearman correlation coefficient & NDI \\
\hline 1 & 0.833 & Test result & Sample size
\end{tabular}

Table 5: Correlation between total score of COMI-Neck questionnaire and SF-36 questionnaire

\begin{tabular}{|c|c|c|c|c|c|c|c|c|c|}
\hline $\begin{array}{l}\text { General } \\
\text { health }\end{array}$ & pain & $\begin{array}{c}\text { Social } \\
\text { function }\end{array}$ & Be good & $\begin{array}{l}\text { energy } \\
\text { fatigue }\end{array}$ & $\begin{array}{l}\text { limitation } \\
\text { emotional }\end{array}$ & limitationphysical & $\begin{array}{l}\text { Function } \\
\text { physical }\end{array}$ & Index & Indices \\
\hline-0.41 & -0.331 & -0.368 & -0.201 & -0.227 & -0.198 & -0.394 & -0.366 & $\begin{array}{l}\text { Spearman } \\
\text { correlation } \\
\text { coefficient }\end{array}$ & \\
\hline $0.000 *$ & $0.001 *$ & $0.000 *$ & $0.045 *$ & $0.023 *$ & $0.049 *$ & $0.000 *$ & $0.000 *$ & Test result & $\begin{array}{l}\text { Total score } \\
\text { COMI-Neck }\end{array}$ \\
\hline 100 & 100 & 100 & 100 & 100 & 100 & 100 & 100 & Sample size & \\
\hline
\end{tabular}

\section{Discussion}

The present study was conducted to determine the psychometric properties of COMI-Neck questionnaire and its reliability and validity in patients with chronic neck pain. The results of the ICC test for each of the five pain indices, with a Cronbach's alpha of over 0.89 , were very high. Also, there was a significant correlation between the total score of COMINeck questionnaire with the total score of FRI and NDI $(P<0.05)$. Based on other results of this study, there was a significant correlation between the score of all indices of COMI-Neck questionnaire with total score of SF $36(P<0.05)$. As the score for COMI-Neck questionnaire indices increased, the total SF 36 score fell sharply.

Therefore, according to the results obtained in this study, the COMI-Neck questionnaire has an appropriate validity and reliability. Therefore, the Persian version of the COMI standard tool can be considered as a tool for assessing the clinical consequences of chronic neck pain in Iranian society. The results of the Fankhauser study that examined the validity and responsiveness of the German version of the COMI using NAAS-Cervical and EQ-5D questionnaires on 134 patients with chronic neck pain, showed an alpha coefficient Cronbach was $96 \%$ of the COMI questionnaire. Moreover, on the other hand, there was a high correlation between the mean score of the COMI questionnaire with each NAAS-Cervical questionnaire $(\mathrm{r}=0.06, P<0.05)$, and a high correlation with the mean scores of EQ- 5D $(\mathrm{r}=0.73, P<0.05)$ suggests that the COMI-Neck is a proper instrument to assess the core outcomes in patients with neck pain (Frankhauser et al., 2012).

Also, the results of the study by Monti cone et al. (2014), which examined the validity and reliability of 
the Italian version of the questionnaire for measuring the core outcomes of chronic neck pain, showed that Cronbach's alpha was $78 \%$, daily work was 0.81 . The index of compatibility with the current symptoms was 0.84 , the quality of life index was 0.78 , the recreation and social activity was 0.88 . The Cronbach's alpha coefficient in the general questionnaire was 0.87 , and in the ICC test was 0.89 , which indicate the acceptable reliability of the Italian version of the questionnaire (Monticone et al., 2014).

The study of Damascene et al. (2012), which examined the cultural adaptation and reliability of the Brazilian-Portuguese version of the COMI questionnaire, showed the Cronbach's alpha coefficient was 96-100 for each of the five indices of the COMI questionnaire. The results of the ICC test showed that the Cronbach's alpha was 0.91-0.96 for each of the five indices of the questionnaire. The results indicate the good validity and reliability of the Brazilian version of the COMI questionnaire.

The results of the Genevay study and its colleagues in 2012 aimed at evaluating the validity and reliability of the French version of core outcome evaluation in patients with low-back pain showed that the Cronbach's alpha was $0.79 \%$ of in the COMI-back questionnaire. According to the obtained Cronbach's alpha from the results of the ICC test, based on the Cronbach's alpha coefficient (0.71-0.91), in the questionnaire indices show the good validity and reliability of this questionnaire in patients with back pain.

In one study conducted by White et al. (2004), with the aim of validating the COMI-Back Questionnaire in patients with neck pain, revealed that the COMI-

\section{References}

Aker, P. D., Gross, A. R., Goldsmith, C. H., \& Peloso, P. (1996). Conservative Management of Mchanical Neck Pain: Systematic Overview and Meta-Analysis. Bmj, 313(7068), 1291-1296.

Ansari, N. N., Naghdi, S., Eskandari, Z., Salsabili, N., Kordi, R., \& Hasson, S. (2016). Reliability and validity of the Persian adaptation of the Core Outcome Measure Index in patients with chronic low back pain. Journal of back is a standard tool for assessing the core outcomes in these patients. The Cronbach's alpha coefficient was significant which showed an acceptable reliability of this questionnaire (Ansari et al., 2016). With regard to these findings which confirm the validity and reliability of the COMI questionnaire as a good tool for measuring the core outcomes of patients with chronic diseases.

This tool providing that is valid can provide critical information for therapists regarding patient treatment. Considering that the provision of standard tools for health related issues, in addition to allowing comparisons of health status among countries, provides valid measures for monitoring the health status at the population level, estimating the burden of the disease, studying outcomes in clinical practice as well as evaluation of therapeutic effects (Taft C, Karlsson J, Sallivan M, 2004; Razavi D, Gandek B. 1998; Manocchia et al., 1996).

\section{Conclusion}

Persian version of COMI-Neck showed acceptable psychometric properties based on consistency, internal consistency, test-retest reliability, and construct validity in patients with neck pain. Therefore, it can be used as a suitable assessment tool for patients with chronic neck pain.

\section{Acknowledgements}

The authors thank all those who helped them writing this paper.

\section{Conflict of interest statement}

Authors declared no conflict of interest.

Orthopaedic Science, 21(6), 723-726.

Bombardier, C. (2000). Outcome Assessments in the Evaluation of Treatment of Spinal Disorders: Summary and General Recommendations. Spine, 25(24), 31003103.

Borghouts, J. A., Koes, B. W., Vondeling, H., \& Bouter, L. M. (1999). Cost-of-illness of Neck Pain in The Netherlands in 1996. Pain, 80(3), 629-636.

Damasceno, L. H. F., Rocha, P. A. G., Barbosa, E. S., 
63. CValidity and Reliability of Persian Version of COMI-Neck......

Barros, C. A. M., Canto, F. T., Defino, H. L. A., \& Mannion, A. F. (2012). Cross-cultural Adaptation and Assessment of the Reliability and Validity of the Core Outcome Measures Index (COMI) for the Brazilian-Portuguese Lnguage. European Spine Journal, 21(7), 1273-1282.

Deyo, R. A., Battie, M., Beurskens, A. J. H. M., Bombardier, C., Croft, P., Koes, B., ... \& Waddell, G. (1998). Outcome Measures for Low Back Pain Research: a Proposal for Standardized Use. Spine, 23(18), 2003-2013.

Fankhauser, C. D., Mutter, U., Aghayev, E., \& Mannion, A. F. (2012). Validity and Responsiveness of the Core Outcome Measures Index (COMI) for the Neck. European Spine Journal, 21(1), 101-114.

Genevay, S., Cedraschi, C., Marty, M., Rozenberg, S., De Goumoëns, P., Faundez, A., ... \& Mannion, A. F. (2012). Reliability and Validity of the Cross-Culturally Adapted French Version of the Core Outcome Measures Index (COMI) in Patients with Low Back Pain. European Spine Journal, 21(1), 130-137.

Mannion, A. F., Boneschi, M., Teli, M., Luca, A., Zaina, F., Negrini, S., \& Schulz, P. J. (2012). Reliability and Validity of the Cross-Culturally Adapted Italian Version of the Core Outcome Measures Index. European Spine Journal, 21(6), 737-749.

Mannion, A. F., Elfering, A., Staerkle, R., Junge, A., Grob, D., Semmer, N. K., ... \& Boos, N. (2005). Outcome Assessment in Low Back Pain: How Low Can You Go?. European Spine Journal, 14(10), 1014-1026.

Manocchia M, Bayliss MS, Connor J, Keller SD, Shiely JC, Tasai C, et al. SF-36 Health Survey Annotated Bibliography: Second Edition (1988-1996). Boston, MA: The Health Assessment Lab, New England Medical Center

Mohammadi, H. R., Azimi, P., Zali, A., \& Montazeri, A. (2015). An outcome Measure of Functionality and Pain in Patients with Low Back Disorder: A validation Study of the Iranian Version of Core Outcome Measures Index. Asian Journal of Neurosurgery, 10(1), 46.

Monticone, M., Ferrante, S., Maggioni, S., Grenat, G.,
Checchia, G. A., Testa, M., ... \& Mannion, A. F. (2014). Reliability, validity and responsiveness of the crossculturally adapted Italian version of the core outcome measures index (COMI) for the neck. European Spine Journal, 23(4), 863-872.

Mousavi, S. J., Parnianpour, M., Montazeri, A., Mehdian, H., Karimi, A., Abedi, M., ... \& Hadian, M. R. (2007). Translation and Validation Study of the Iranian Versions of the Neck Disability Index and the Neck Pain and Disability Scale. Spine, 32(26), E825-E831.

Qiao, J., Zhu, F., Zhu, Z., Xu, L., Wang, B., Yu, Y., ... \& Qiu, Y. (2013). Validation of the Simplified Chinese Version of the Core Outcome Measures Index (COMI). European Spine Journal, 22(12), 2821-2826.

Razavi, D., \& Gandek, B. (1998). Testing Dutch and French translations of the SF-36 Health Survey among Belgian angina patients. Journal of clinical epidemiology, 51(11), 975-981.

Schellingerhout JM, Virage AP, Heymans MW, Kores BW, Henrico C, Tarweed, CB, Measurement properties of disease-specific questionnaires in patients with neck pain: a systematic review, Quality Life Res .2012; 21(4): 659-70.

Taft, C., Karlsson, J., \& Sullivan, M. (2004). Performance of the Swedish SF-36 version 2.0. Quality of Life Research, 13(1), 251-256.

Terwee, C. B., Bot, S. D., de Boer, M. R., van der Windt, D. A., Knol, D. L., Dekker, J., ... \& de Vet, H. C. (2007). Quality Criteria Were Proposed for Measurement Properties of Health Status Questionnaires. Journal of Clinical Epidemiology, 60(1), 34-42.

White, P., Lewith, G., \& Prescott, P. (2004). The core outcomes for neck pain: validation of a new outcome measure. Spine, 29(17), 1923-1930.

Zweig, T., Mannion, A. F., Grob, D., Melloh, M., Munting, E., Tuschel, A., ... \& Röder, C. (2009). How to Tango: A Manual for Implementing Spine Tango. European Spine Journal, 18(3), 312-320. 


\section{مقالة يزوهشى \\ بررسى روايى و يايايى نسخةُ فارسى يرسشنامه COMI در بيماران ايرانى

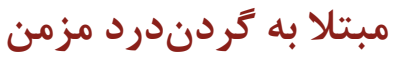

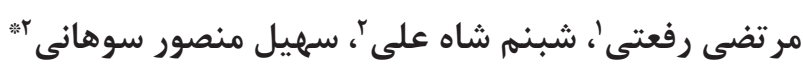

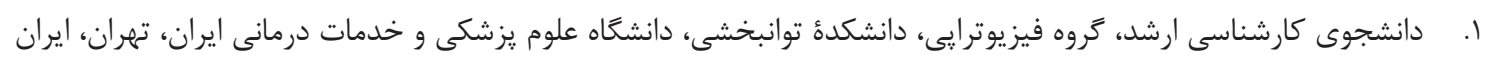

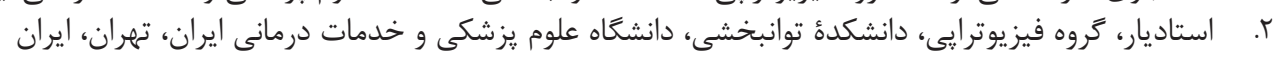

\begin{tabular}{|c|c|}
\hline جكيده & اطلاعات مقاله \\
\hline 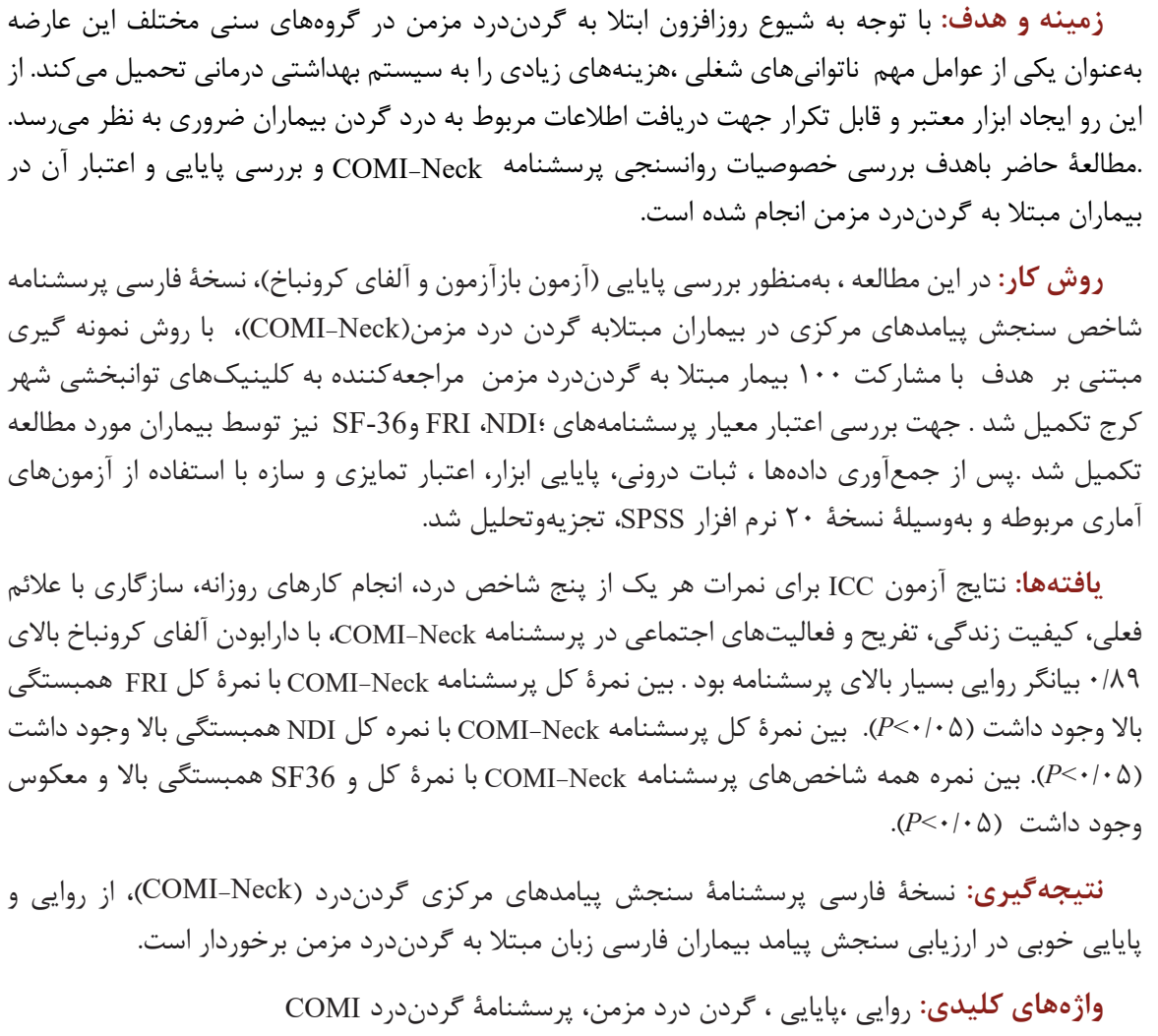 & 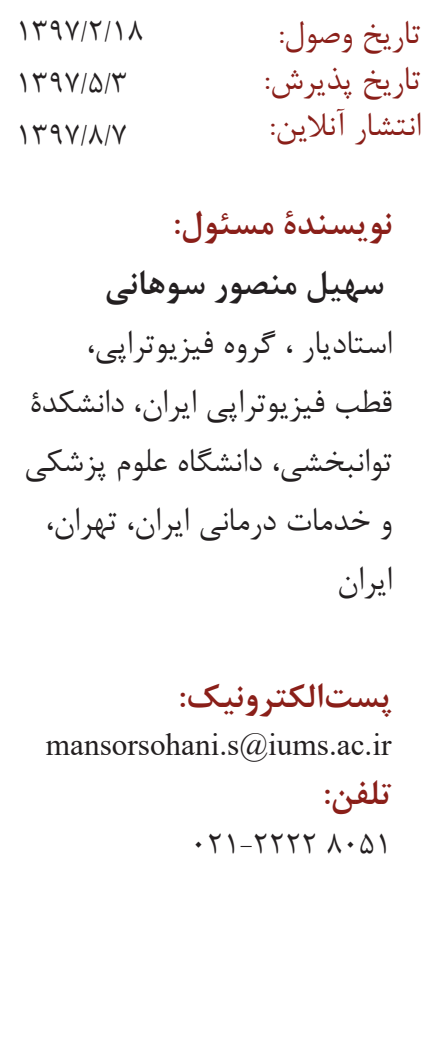 \\
\hline
\end{tabular}

